\title{
Questing Ixodes ricinus ticks (Acari, Ixodidae) as a vector of Borrelia burgdorferi sensu lato and Borrelia miyamotoi in an urban area of north-eastern Poland
}

\author{
Katarzyna Kubiak ${ }^{1}$ (D) . Janina Dziekońska-Rynko² • Hanna Szymańska • \\ Dariusz Kubiak $^{3}$ - Małgorzata Dmitryjuk ${ }^{4}$ Ewa Dzika ${ }^{1}$
}

Received: 16 January 2019 / Accepted: 13 May 2019 / Published online: 17 May 2019

(c) The Author(s) 2019

\begin{abstract}
Green areas located within large cities, as natural ecotypes, are a convenient habitat for ticks and their use as recreational areas is associated with the potential risk of acquiring tick-borne diseases. This study estimated the I. ricinus tick density, prevalence of infection with Borrelia species and the diversity of these bacteria in a green urban area (Olsztyn) of north-eastern Poland, an endemic region of tick-borne diseases. The ticks were collected during spring and autumn of 2015, at sites differing in the degree of human pressure and habitat. Borrelia species detection, typing and a molecular phylogenetic analysis were carried out based on the sequenced $f l a B$ gene. The overall mean abundance of I. ricinus was $2.0 \pm 1.55$ ticks per $100 \mathrm{~m}^{2}$. The density of $I$. ricinus did not vary significantly between sites. According to semi-qualitative tick abundance categories, the collection sites were classified as 'very low' and 'low' tick abundance category. The overall infection rate of I. ricinus with Borrelia spirochaetes was $27.4 \%$. The infection rate of adult ticks $(42.0 \%)$ was three times higher than with nymphs $(14.3 \%)$. Based on the restriction patterns and sequencing, B. afzelii $(93.1 \%$; 27/29), B. valaisiana $3.5 \%(1 / 29)$ and B. miyamotoi $(3.5 \%$; $1 / 29$ ), related to the relapsing fever (RF) spirochaetes, were detected. No co-infections were found. Borrelia miyamotoi, detected for the first time in ticks in the north-eastern urban areas of Poland, was identical to isolates described as European-type. The Borrelia spirochaete infection rate of $I$. ricinus ticks in an urban area indicated a high risk of LB. Physicians should also be aware of $B$. miyamotoi infections among patients with a history of tick-bites in north-eastern Poland.
\end{abstract}

Keywords Ixodes ricinus $\cdot$ Borrelia burgdorferi sensu lato complex $\cdot$ Borrelia miyamotoi . Urban area Poland

Katarzyna Kubiak

katarzyna.kubiak@uwm.edu.pl

Extended author information available on the last page of the article 


\section{Introduction}

In Europe, the Ixodes ricinus tick is the most widespread reservoir and vector of many pathogenic agents (viruses, bacteria and protozoa) of medical and veterinary importance (Medlock et al. 2013; Parola and Raoult 2001; Parola and Paddock 2018). Due to the increasing tick-borne disease (TBDs) incidence rate and the confirmed pathogenicity of new microorganism species transmitted by ticks, most of the tick-transmitted diseases are classified as emerging infectious diseases (EIDs) (Jongejan and Uilenberg 2004; Vorou et al. 2007; Vu Hai et al. 2014). The most commonly diagnosed tick-borne disease in humans is Lyme borreliosis (LB), caused by spirochaetes of the Borrelia burgdorferi complex (Medlock et al., 2018). In this group comprising 20 species, five (B. burgdorferi s.s., B. afzelii, B. garinii, $B$. bavariensis and $B$. spielmanii) are regarded as human pathogens (Jungnick et al. 2015; Margos et al. 2011). The pathogenicity of B. valaisana, B. bissetti and B. lusitaniae is also not excluded (Derdáková and Lenčáková 2005; Diza et al. 2004; Jungnick et al. 2015; Margos et al. 2017; Stanek and Reiter 2011). Different Borrelia species and/or genotypes implicated in the infection cause a broad spectrum of the clinical picture of LB, covering various tissues and organs, including skin, joints, heart and nervous system, with the course of illness from acute to chronic (Stanek and Reiter 2011). In Europe, 85,999 LB cases are recorded per year (Pritt et al. 2016). In Poland, in 2015-2017, LB was diagnosed in approximately 19,000 patients a year. The largest number of LB cases were found in north-eastern Poland (the Warmia-Mazury province), where the incident rate was almost twice as high as in the rest of the country (NIH-PZH). The involvement of I. ricinus ticks in B. miyamotoi transmission-a species closely related to LB Borrelia spirochaetes and belonging to the relapsing fever (RF) group of Borrelia has also been confirmed (Fukunaga et al. 1995; Richter et al. 2003). Until 2011, when the first symptomatic infection in human was recorded in Russia, B. miyamotoi had been regarded as a non-pathogenic species (Platonov et al. 2011). Since that time, subsequent cases of infection with B. miyamotoi in humans have been noted in the USA (Krause et al. 2013; Molloy et al. 2015), Europe (The Netherlands, Germany) (Hansford et al. 2015; Hovius et al. 2013; Jahfari et al. 2016) and Japan (Sato et al. 2014). Symptoms of infection caused by B. miyamotoi (Borrelia miyamotoi disease-BMD) are non-specific and diverse. In patients, BMD manifests itself with high fever (up to $40{ }^{\circ} \mathrm{C}$ ), fatigue, headaches, chills, myalia, arthralgia and nausea; meningoencephalitis may also develop (Platonov et al. 2011).

In many European cities, the tendency to preserve green areas, such as parks and forests, undeveloped squares, old cemeteries and gardens, creates favourable conditions for the development of populations of small and medium-size mammals. This group of animals, as hosts, help to maintain and spread tick populations in urban areas. On the other hand, green city areas are also used by urban dwellers and their companion animals for recreational activities, which increases the risk of acquiring a tick-borne disease through regular exposure to tick bites (Uspensky 2014). Once of the measures for estimating the risk of tick-borne diseases is monitoring questing tick distribution and their population density in an area, and an assessment of the level of their infection with pathogens (Kilpatrick et al. 2017; Vu Hai et al. 2014). This approach is of key importance for undertaking the appropriate prophylactic and educational measures.

Due to the high LB and tick-borne encephalitis incidence rate in the inhabitants, the region of north-eastern Poland is regarded as endemic for tick-borne diseases (NIH-PZH). The risk of acquiring tick-borne diseases in this area of Poland is usually connected with staying in an area of low anthropopressure-forest ecotypes or rural areas-the habitats 
typical of I. ricinus ticks and their hosts (Pawelczyk and Sinski 2001, 2004; Stańczak et al. 2000; Stańczak and Kubica-Biernat 1999). Due to the lack of data about the ticks and tickborne pathogens in urban areas in this region, the aim of the study was to determine the role of $I$. ricinus ticks as a vector of microorganisms of the Borrelia genus in city areas of north-eastern Poland.

\section{Materials and methods}

\section{Study area, tick collection}

The study was conducted in three green recreational areas in the city of Olsztyn $\left(53^{\circ} 46^{\prime} 23^{\prime \prime} \mathrm{N} 20^{\circ} 28^{\prime} 34^{\prime \prime} \mathrm{E} ; 88.0 \mathrm{~km}^{2} ; 173444\right.$ residents), the capital of the province of Warmia-Mazury (north-eastern Poland) (Fig. 1). The tick collection sites (surfaces of $350-400 \mathrm{~m}^{2}$ ) differed in the degree of human pressure and habitat (Table 1). At each site, the questing I. ricinus ticks were collected between April-May and September 2015 during the daytime between 9 a.m. and 4 p.m. by one person for at least $30 \mathrm{~min}$ using the standard flagging method. In the laboratory, the collected ticks were identified by species, sex and developmental stage using taxonomic keys (Nowak-Chmura 2013; Siuda 1993) and preserved in $70 \%$ ethanol for further molecular investigation. For each collection site, tick abundance was calculated as the number of specimens collected per $100 \mathrm{~m}^{2}$ for each individual flagging event.

\section{DNA extraction}

Prior to DNA extraction, the ticks were air-dried for several minutes and then individually cut with a sterile scalpel. Genomic DNA extraction from ticks was carried out by universal kit Sherlock AX (A\&A Biotechnology, Poland) according to the manufacturer's instructions. DNA was eluted in $40 \mu \mathrm{L}$ of TE buffer and stored at $-20{ }^{\circ} \mathrm{C}$ for further analysis.

Fig. 1 Locations of the study area in north-eastern Poland

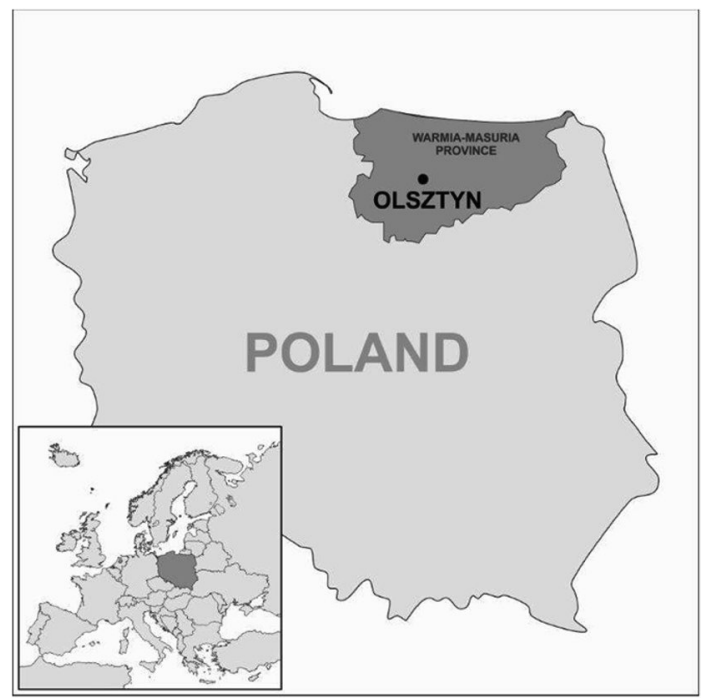




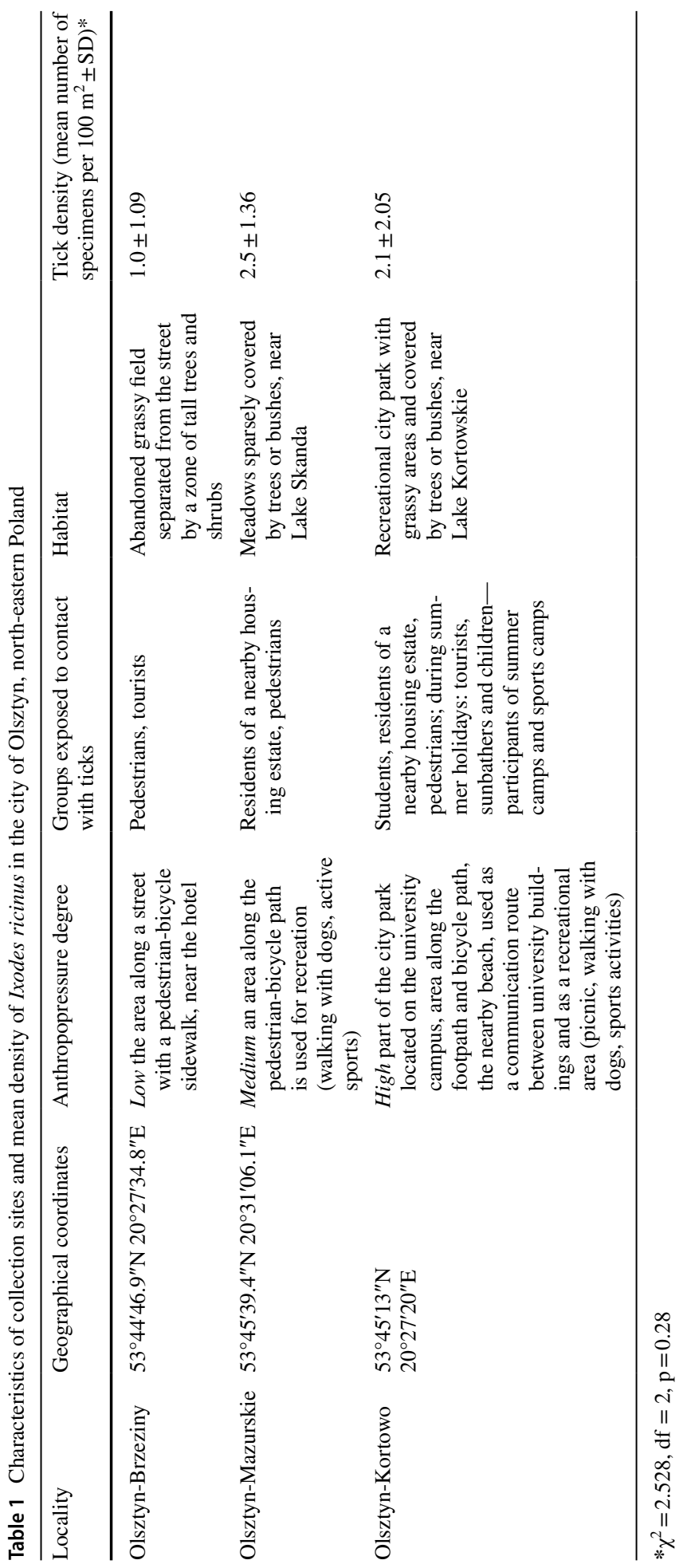




\section{Detection and identification of spirochaete DNA by the nested PCR-RFLP method}

The presence of Borrelia spirochaetes in tick genomic DNA samples was confirmed by the nested polymerase chain reaction (PCR) method using two sets of primers specific to the flagellin gene $(f l a B)$ : outer-132f/905r (774 bp) and inner-220f/823r (604 bp) (Wodecka et al. 2010). The $25 \mu \mathrm{L}$ of PCR mixture contained $12.5 \mu \mathrm{L}$ of $2 \times$ PCR Master Mix Plus $\left(0.1 \mathrm{U} / \mu \mathrm{L}\right.$ of $T a q$ polymerase supplied in a PCR buffer, $4 \mathrm{mM}$ of $\mathrm{MgCl}_{2}$ and $0.5 \mathrm{mM}$ of each dNTPs); (A\&A Biotechnology, Poland), $0.5 \mu \mathrm{L}$ of each primer $(10 \mathrm{mM}), 10.5 \mu \mathrm{L}$ sterile nuclease-free water and $1 \mu \mathrm{L}$ of template DNA or $1 \mu \mathrm{L}$ of the outer PCR product for nested PCR. The thermal conditions of PCRs were: $5 \mathrm{~min}$ at $94{ }^{\circ} \mathrm{C}$, followed by 40 cycles of $30 \mathrm{~s}$ at $94{ }^{\circ} \mathrm{C}, 30 \mathrm{~s}$ at $53{ }^{\circ} \mathrm{C}\left(54{ }^{\circ} \mathrm{C}\right.$ for inner primers $), 30 \mathrm{~s}$ at $72{ }^{\circ} \mathrm{C}$ and a final extension of $7 \mathrm{~min}$ at $72{ }^{\circ} \mathrm{C}$ (iCycler MyiQ, Bio-Rad, USA). DNA isolated from B. afzelii positive $I$. ricinus tick (confirmed by sequencing) and nuclease-free water were run in each analysis as positive and negative controls. Nested PCR products were separated on $2 \%$ agarose gels stained with ethidium bromide and visualized using GelDocXR (Bio-Rad, USA).

To the identification of Borrelia species, the restriction fragment length polymorphism (RFLP) method was used. The positive inner PCR products (604 bp) were digested with the restriction enzyme HpyF3I (DdeI) (ThermoFisher Scientific, USA) according to the manufacturer's instructions. Restriction fragments were separated on 3\% agarose gel stained with ethidium bromide. Recognition of the species was based on the RFLP patterns given by Wodecka 2011 and Wodecka et al. 2010.

\section{DNA sequencing}

To confirm PCR-RFLP results chosen, positive inner PCR products were purified using the Clean Up purification kit (A\&A Biotechnology, Poland) according to the manufacturer's protocol and sequenced bi-directionally with inner primers (220f/823r) (Macrogen Europe, the Netherlands). The obtained nucleotide sequences were edited in BioEdit software (Hall 1999) and compared with data registered in the GenBank database (http://www.ncbi.nih. gov/Genbank/index.html) using the BLAST-NCBI program (http://www.ncbi.nlm.nih.gov/ BLAST/). Consensus Borrelia flaB gene sequences were deposited in the GenBank database and registered under the accession numbers MK059480-MK059484.

\section{Phylogenetic analysis}

Nine representative Borrelia sequences obtained from the collected I. ricinus ticks and the most similar chosen reference sequences from GenBank were used in phylogenetic analysis. The phylogram was constructed using the Maximum Likelihood method based on the Kimura 2-parameter model (Kimura, 1980). The topology of the phylogenetic tree was evaluated using the bootstrap method with 1000 replicates. Phylogenetic analysis was conducted using MEGA v.6.06 software (Tamura et al. 2013).

\section{Statistical analysis}

The differences in the abundance of $I$. ricinus ticks between collection sites were analysed using the one way non-parametric ANOVA (Kruskal-Wallis H test). A Chi square test was 
used to compare the infection prevalence of Borrelia species between developmental stages of ticks and study areas. In both tests, the differences were considered to be statistically significant when the $p$ value was less than 0.05 . The analysis was conducted using the software package SPSS version 22.0 for Windows (SPSS Inc., Chicago, IL).

\section{Results}

\section{Tick abundance}

Among 106 collected questing I. ricinus ticks, 50 (48\%) adult specimens (30 females and 20 males) and 56 (52\%) nymphs were identified. The overall mean abundance was $2.0 \pm 1.55$ ticks per $100 \mathrm{~m}^{2}$. The density of $I$. ricinus did not vary significantly $\left(\chi^{2}=2.528\right.$; $\mathrm{df}=2 ; \mathrm{p}=0.28$ ) between sites and it ranged from $1.0 \pm 1.09$ (Brzeziny) to $2.5 \pm 1.36$ (Mazurskie) ticks per $100 \mathrm{~m}^{2}$ (Table 1). According to semi-qualitative tick abundance categories (Schwarz et al. 2009), the collection sites were classified as 'very low tick abundance' (Brzeziny and Kortowo) or 'low tick abundance' (Mazurskie).

\section{Prevalence of spirochaetes}

The overall prevalence of Borrelia spp. and B. miyamotoi spirochaetes in I. ricinus was $27.4 \%$ (29/106) (Table 2). The infection rate of adult ticks $(42.0 \% ; 21 / 50)$ was three times higher than nymphs $(14.3 \% ; 8 / 56)$. Females showed an infection rate of $43.3 \%(13 / 30)$ whereas $40 \%$ (8/20) of males were Borrelia-positive. The differences in infection rates between tick developmental stages were statistically significant $\left(\chi^{2}=10.276 ; \mathrm{df}=2\right.$; $\mathrm{p}=0.006)$. Borrelia species were detected in I. ricinus from all study sites. The infection rate did not differ between collection sites $\left(\chi^{2}=2.055 ; \mathrm{df}=2 ; \mathrm{p}=0.36\right)$ and ranged from $18.2 \%$ (Kortowo) to $33.3 \%$ (Brzeziny) (Table 2).

Table 2 Infection rates of Ixodes ricinus ticks with Borrelia species according to the tick developmental stages and locality in urban areas of Olsztyn, north-eastern Poland

\begin{tabular}{lcclll}
\hline & No. (\%) of collected & \multicolumn{2}{c}{ No. (\%) positive for each Borrelia species } & Total no. (\%) of infected \\
\cline { 3 - 5 } & & B. afzelii & B. valaisiana & B. miyamotoi & \\
\hline Stage & & & & & \\
Females & $30(28.3)$ & $11(84.6)$ & $1(7.7)$ & $1(7.7)$ & $13(43.3)^{*}$ \\
Males & $20(18.9)$ & $8(100)$ & $0(0)$ & $0(0)$ & $8(40.0)^{*}$ \\
Nymphs & $56(52.8)$ & $8(100)$ & $0(0)$ & $0(0)$ & $8(14.3)^{*}$ \\
Locality & & & & & \\
Brzeziny & $12(11.3)$ & $3(75.0)$ & $0(0)$ & $1(25.0)$ & $4(33.3)^{* *}$ \\
Mazurskie & $61(57.5)$ & $18(94.7)$ & $1(5.3)$ & $0(0)$ & $19(31.1)^{* *}$ \\
Kortowo & $33(31.1)$ & $6(100)$ & $0(0)$ & $0(0)$ & $6(18.2)^{* *}$ \\
Total & $106(100)$ & $27(93.1)$ & $1(3.5)$ & $1(3.5)$ & $29(27.4)$ \\
\hline
\end{tabular}

$*\left(\chi^{2}=10.276, \mathrm{df}=2, \mathrm{p}=0.006\right) ; * *\left(\chi^{2}=2.055, \mathrm{df}=2, \mathrm{p}=0.36\right)$ 


\section{Genotyping and diversity of spirochaetes}

Based on the restriction patterns obtained after digestion, $604 \mathrm{bp}$ fragments of the $f a B$ gene B. afzelii $(305,165,94,40 \mathrm{bp}$; pattern II), B. valaisiana $(188,135,117,92,72 \mathrm{bp}$; pattern VI) and B. miyamotoi (512, $86 \mathrm{bp}$; pattern IX) were detected (Fig. 2). The dominant pathogen species was B. afzelii $(93.1 \%, 27 / 29)$. B. valaisiana was identified in $3.5 \%(1 / 29)$ and B. miyamotoi in 3.5\% (1/29) (Table 2). No co-infections were found.

To confirm PCR-RFLP results, positive inner PCR of B. afzelii $(\mathrm{n}=7)$, B. valaisiana $(\mathrm{n}=1)$ and $B$. miyamotoi $(\mathrm{n}=1)$ products were sequenced. Among $B$. afzelii, three variants of $f a B$ gene sequences were identified. One of the most frequent variants (BaOL1, MK059480), recognized in four isolates, was identical with the pathogenic $\mathrm{BO} 23$ B. afzelii strain (CP018262) isolated from the skin of German patients and sequences detected in the blood of Apodemus flavicolis (KY626319) and questing I. ricinus from Poland (Fig. 3). In other variants (BaOL2, MK059482 and BaOL3, MK059481), nucleotide substitutions were noted. In the BaOL2 variant, substitution in one nucleotide position (1 SNP) did not change the amino-acid sequence. In BaOL3, the variant nucleotide variation in position three ( $3 \mathrm{SNP}$ ) changed the amino-acid flagellin sequence. FlaB sequences of B. valaisiana (MK059484) were identical to BvV2 variant (MF150078) of this species detected in I. ricinus from Białowieża National Park in north-eastern Poland and displayed high similarity to sequences from questing I. ricinus in Poland and Turkey (Fig. 3). The B. miyamotoi flaB gene sequence (MK059483) was identical to the sequences of isolate Mos-80(1) of B. miyamotoi from Russian I. ricinus designated as European-type (Platonov et al. 2011; Takano et al. 2014). On the phylogram, this sequence (clustered together with other sequences) was detected in I. ricinus from different parts of Poland and Czech Republic (Fig. 3).

M B.a. B.a. B.a. B.a. B.a. B.m. B.a. B.a. B.a. B.a. B.a. B.a. B.a. B.v. B.a. B.a.

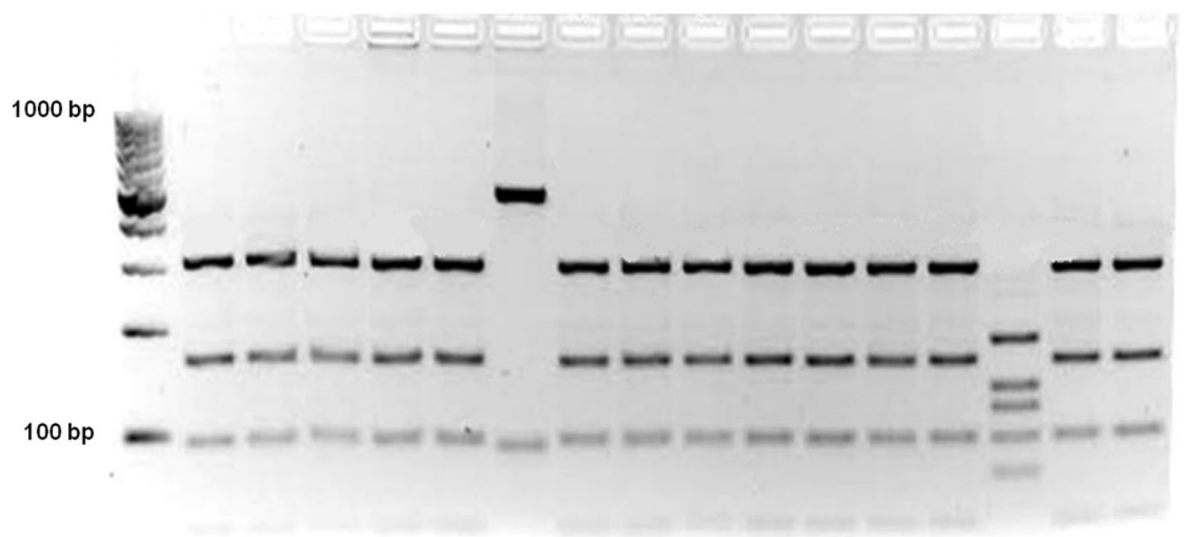

Fig. 2 The RFLP patterns obtained after DdeI enzyme digestion of positive nested-PCR products (604 bp): M-DNA size marker; B.a. Borrelia afzelii; B.m. B. miyamotoi; B.v. B. valaisiana 


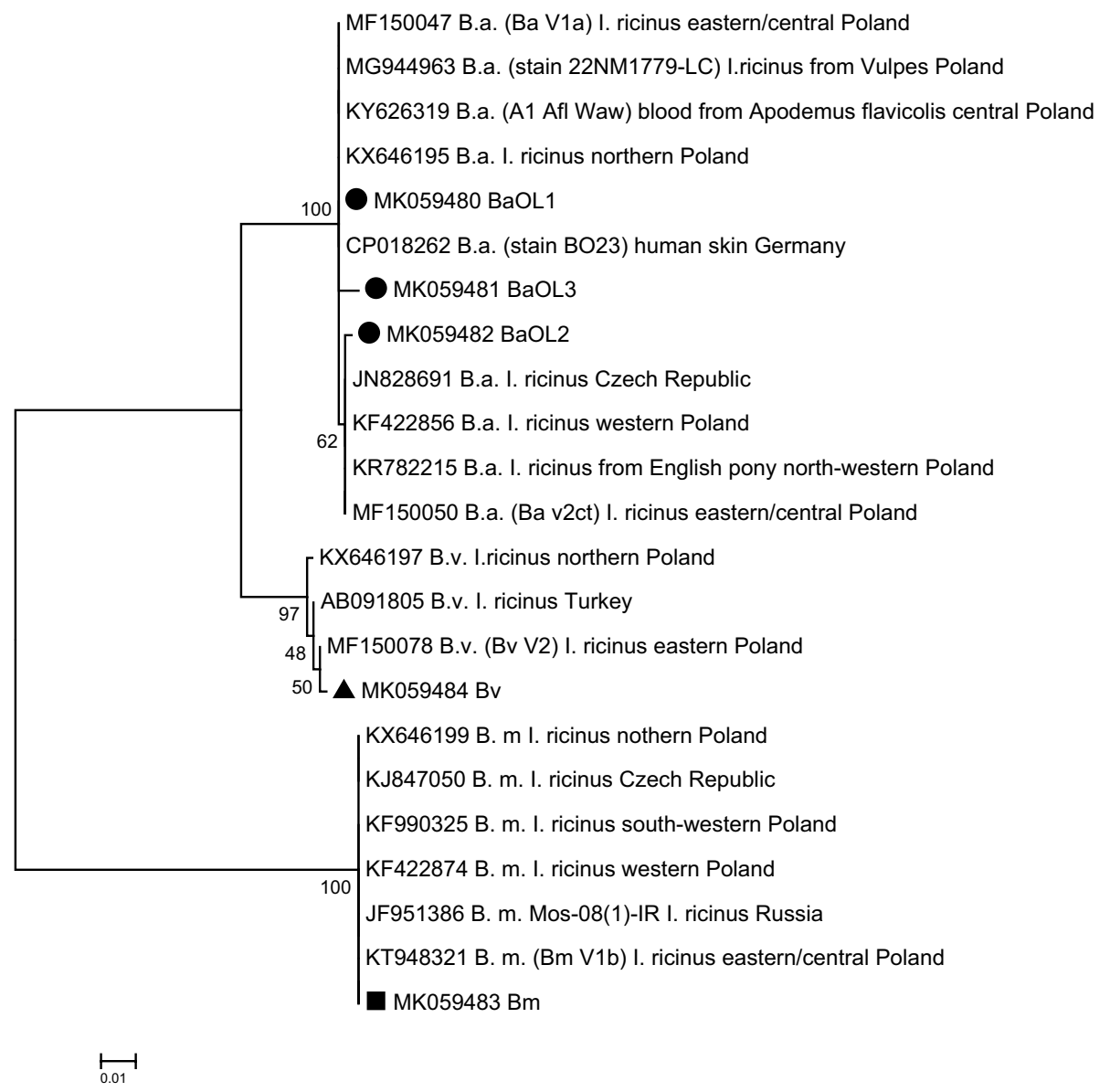

Fig. 3 Phylogram constructed based on partial sequences of $f a B$ gene by using the Maximum Likelihood method with the Kimura 2-parameter model. The percentage of trees in which the associated taxa clustered together is shown next to the branches. The tree is drawn to scale, with branch lengths measured in the number of substitutions per site. Numbers at the nodes of the tree indicated bootstrap values (1000 replicates). The analysis involved 23 nucleotide sequences. There were a total of 527 positions in the final dataset. Evolutionary analyses were conducted in MEGA6. The sequences obtained in this study were labelled with black symbols. B.a. Borrelia afzelii, B.v. B. valaisiana, B.m. B. miyamotoi

\section{Discussion}

Areas situated within the administrative boundaries of large European cities, have repeatedly been indicated as an environment favourable to I. ricinus ticks (Didyk et al. 2017; Hansford et al. 2017; Kowalec et al. 2017; Uspensky 2014). The average tick population density in habitats located in urban areas is nearly 2-3 times lower compared to natural ecotypes (Dobson et al. 2011; Hamšíková et al. 2017; Kowalec et al. 2017; Kubiak and Dziekońska-Rynko 2006). The results of our study indicate that urban areas in north-eastern Poland are not safe regarding the risk of LB and other TBDs. Regardless of the degree of anthropopressure, the collection sites in Olsztyn were classified as "low" or "very low" 
in tick abundance (Schwarz et al. 2009), with the mean tick I. ricinus population density ranging from 1.0 to 2.1 specimens per $100 \mathrm{~m}^{2}$. Such a low population density must be associated with the specimen collection sites located in typical recreational areas and not connected with large forest complexes, which considerably limits the accessibility of mediumsize and large I. ricinus hosts. Limiting access to hosts has also been identified as a factor which reduced the density of I. ricinus ticks in parks in Warsaw by half compared to a large forest complex situated within the administrative boundaries of the city (Kowalec et al. 2017). Apart from the tick abundance, the risk of contracting TBDs is affected by human behaviour patterns, which bring people in contact with the habitats resided by ticks (Kilpatrick et al. 2017; Randolph and EDEN-TBD sub-project team 2010; Rizzoli et al. 2014). Exposure to I. ricinus ticks and infection with TBDs is associated with fresh air activities (Lane et al., 2004; Padgett and Bonilla 2011; Randolph and EDEN-TBD subproject team 2010; Wierzbicka et al. 2016). In the green areas covered by our study, these activities include walking, jogging, walking pets or behaviour which necessitates direct contact with the ground and forest litter, such as resting on the grass or using wooden logs or tree trunks as picnic sites. The risk of contracting TBDs is also significantly affected by the level of infection of ticks and the species composition of the pathogens (Kilpatrick et al. 2017). Infection of I. ricinus with spirochaetes of the B. burgdorferii s.l. complex is diverse, not only in Europe (3.6-19.3\%) (Strnad et al. 2014), but also within a specific country. In Poland, the I. ricinus infection rate varies from 1.2 to $12.4 \%$ depending on the region (Karbowiak et al. 2018). Data on the level of infection of the population of I. ricinus with B. burgdorferi spirochaetes in north-eastern Poland date from the turn of the 21 st century. At that time, it was indicated that prevalence of Borrelia in I. ricinus ranges from 10.3 to $23.1 \%$, depending on the study year (Pawelczyk and Sinski 2001, 2004; Stańczak et al. 2000; Stańczak and Kubica-Biernat 1999). Only B. garinii and B. afzelii were found in this area, which was probably due to the identification methods applied (Stańczak et al. 2000). The level of $27 \%$ of infected I. ricinus in urban areas of north-eastern Poland that we established in our study is much higher and it did not differ significantly between the study sites. The level of infection of $I$. ricinus ticks in Olsztyn was also much higher compared to the green areas in other large cities, such as Kiev 4\% (Didyk et al. 2017), Warsaw 10.9\% (Kowalec et al. 2017), Luxembourg 11.3\% (Reye et al. 2010), Salisbury 18.1\% (Hansford et al. 2017). A comparable or higher level was recorded only in large cities in GermanyHanover (22.7\%) (Tappe et al. 2014) and Hamburg (34.1\%) (May et al. 2015). The data for Olsztyn confirmed the general trend that the level of infection of adult ticks is much higher than that of nymphs (Karbowiak et al. 2018; Strnad et al. 2014). The infection rate of adult ticks $(42.0 \%)$ was three times higher than nymphs $(14.3 \%)$.

However, human impact on the environment in urban areas and the connected lower tick abundance do not have an effect on the prevalence of Borrelia spirochaetes I. ricinus (Kowalec et al. 2017). Comparison of populations of I. ricinus in urban areas in central Poland and natural areas in eastern Poland indicated a similar level of spirochaetes infections (10.9\% vs. $12.2 \%$, respectively) (Kowalec et al. 2017). The diversity of spirochaetes in $I$. ricinus ticks in these two types of environment was also comparable. However, our study did not demonstrate such a rich species composition, which is probably caused by the small number of ticks taken for examination. Among nine species from the B. burgdorferii s.l. complex recorded in Europe and six identified by Kowalec et al. (2017) in natural habitats in eastern Poland, the I. ricinus ticks in Olsztyn were found to be infected only with $B$. afzelii and B. valaisiana. We also confirmed a high percentage of a human pathogen $B$. afzelii (93.1\%) in the infected ticks, which suggests a high risk of LB with skin symptoms of infection. A meta-analysis of 2010-2016 data concerning the species composition of 
Borrelia spirochaetes in ticks from 23 European countries, indicated $B$. afzelii to be the most commonly identified species (Strnad et al. 2014). B. afzelii was the dominant species in the population of infected I. ricinus ticks in the green areas of Warsaw (Kowalec et al. 2017), Hanover (Tappe et al. 2014), Kiev (Didyk et al. 2017) and Luxembourg (Reye et al. 2010). However, the second most common species—B. garinii, which dominates among the infected ticks in forested areas in Bratislava (Chvostáč et al. 2018) and Salisbury (Hansford et al. 2017) and in natural ecotypes in the east of Poland (Kowalec et al. 2017), was not detected. These differences are probably associated with the group of I. ricinus available hosts. B. afzelii is associated with rodents, whereas B. garinii with birds. Birds are also involved in the transmission of $B$. valaisiana - a species whose human pathogenicity is poorly documented but detected in questing ticks from green areas of Olsztyn and other cities (Chvostáč et al. 2018; Hansford et al. 2017; Kowalec et al. 2017; Tappe et al. 2014).

Of particular interest is the detection of B. miyamotoi. We revealed the occurrence of this pathogen in Olsztyn for the first time and it was confirmed in the subsequent year of the study (unpublished data). The sequence of the B. miyamotoi flaB gene fragment identified in our study is identical to the sequences in European-type B. miyamotoi (Platonov et al. 2011; Takano et al. 2014). According to Kowalec et al. (2017), within Europeantype $B$. miyamotoi there may be a specific Polish strain of this pathogen, which is also present in I. ricinus in the area of Olsztyn. The low prevalence of B. miyamotoi $(3.5 \%$, $1 / 106)$ estimated in our study is typical of Europe. The I. ricinus infection rate in many European countries ranges from $0.16 \%$ in Portugal (Nunes et al. 2015) to $4.8 \%$ in Hungary (Szekeres et al. 2015). In Poland, B. miyamotoi was identified in I. ricinus in recreational areas in Szczecin (Wodecka et al. 2010) and Warsaw (Kowalec et al. 2017) and in natural habitats of Lower Silesia (Kiewra et al. 2014) and eastern Poland (Kowalec et al. 2017) with a low prevalence from 0.5 to $3.9 \%$. The relatively low infection rate of $B$. miyamotoi in questing Ixodes spp. can be caused by an adverse effect of spirochaetes on the survival rate of infected ticks or by the low rate of ticks acquiring it when feeding on infected hosts (Barbour et al. 2009; Wagemakers et al. 2015). However, it does not rule out the possibility of the incidence of BMD in areas endemic to LB and other TBDs, especially since the co-infection of B. miyamotoi with other pathogens has been observed, both in vectors (Kiewra et al. 2014; Wagemakers et al. 2015) and in patients (Platonov et al. 2011). Fiecek and Chmielewski (2017) note that a BMD should be considered in patients with high fever or neurological symptoms, in whom anti-Borrelia antibodies are detected only in serum. This group of neurological patients do not meet the criteria for neuroborreliosis. In Poland, most cases of neuroborreliosis are registered as probable cases with unconfirmed diagnosis by the presence of anti-Borrelia antibodies in cerebrospinal fluid (CSF) (Fiecek and Chmielewski 2017).

\section{Conclusion}

The high Borrelia infection rate of $I$. ricinus ticks revealed in Olsztyn confirms that green areas in the cities located in areas endemic to TBDs, such as north-eastern Poland, is linked to a high risk of LB, despite a low I. ricinus abundance. Domination of the human pathogen $B$. afzelii among infected I. ricinus ticks suggests that residents with borreliosis will primarily reveal skin symptoms of this disease. Although there is a low prevalence of the pathogenic species of B. miyamotoi, cases of BMD should be considered in patients declaring tick bites, especially in patients with high fever and meningoencephalitis, without 
anti-Borrelia antibodies in CSF. A comprehensive study must be conducted in north-eastern Poland to determine the B. miyamotoi prevalence in I. ricinus ticks and take measures to educate and raise awareness of TBD presence other than LB, not only among residents, but also among physicians.

Acknowledgements We would like to thank Pabianek A. for technical assistance and Tański A. (Department of Medical Biology, UWM in Olsztyn) for drawing the map (Fig. 1).

Open Access This article is distributed under the terms of the Creative Commons Attribution 4.0 International License (http://creativecommons.org/licenses/by/4.0/), which permits unrestricted use, distribution, and reproduction in any medium, provided you give appropriate credit to the original author(s) and the source, provide a link to the Creative Commons license, and indicate if changes were made.

\section{References}

Barbour AG, Bunikis J, Travinsky B et al (2009) Niche partitioning of Borrelia burgdorferi and Borrelia miyamotoi in the same tick vector and mammalian reservoir species. Am J Trop Med Hyg 81:11201131. https://doi.org/10.4269/ajtmh.2009.09-0208

Chvostáč M, Spitalská E, Václav R et al (2018) Seasonal patterns in the prevalence and diversity of TickBorne Borrelia burgdorferi sensu lato, Anaplasma phagocytophilum and Rickettsia spp in an urban temperate forest in South Western Slovakia. Int J Environ Res Public Health. https://doi.org/10.3390/ ijerph15050994

Derdáková M, Lenčáková D (2005) Association of genetic variability within the Borrelia burgdorferi sensu lato with the ecology, epidemiology of Lyme borreliosis in Europe. Ann Agric Environ Med 12:165172. https://doi.org/10.1080/0816464042000334582

Didyk YM, Blaňárová L, Pogrebnyak S et al (2017) Emergence of tick-borne pathogens (Borrelia burgdorferi sensu lato, Anaplasma phagocytophilum, Ricketsia raoultii and Babesia microti) in the Kyiv urban parks, Ukraine. Ticks Tick Borne Dis 8:219-225. https://doi.org/10.1016/j.ttbdis.2016.10.002

Diza E, Papa A, Vezyri E et al (2004) Borrelia valaisiana in cerebrospinal fluid. Emerg Infect Dis 10:16921693. https://doi.org/10.3201/eid1009.030439

Dobson ADM, Taylor JL, Randolph SE (2011) Tick (Ixodes ricinus) abundance and seasonality at recreational sites in the UK: Hazards in relation to fine-scale habitat types revealed by complementary sampling methods. Ticks Tick Borne Dis 2:67-74. https://doi.org/10.1016/j.ttbdis.2011.03.002

Fiecek B, Chmielewski T (2017) Borrelia miyamotoi-new etiologic agent of neuroborreliosis? Przegl Epidemiol 71:531-538

Fukunaga M, Takahashi Y, Tsuruta Y et al (1995) Genetic and phenotypic analysis of Borrelia miyamotoi sp. nov., isolated from the ixodid tick Ixodes persulcatus, the vector for Lyme disease in Japan. Int J Syst Bacteriol 45:804-810. https://doi.org/10.1099/00207713-45-4-804

Hall TA (1999) BioEdit: a user-friendly biological sequence alignment editor and analysis program for Windows 95/98/NT. Nucleic Acids Symp Ser 41:95-98

Hamšíková Z, Coipan C, Mahríková L et al (2017) Borrelia miyamotoi and co-infection with Borrelia afzelii in Ixodes ricinus ticks and rodents from Slovakia. Microb Ecol 73:1000-1008. https://doi.org/10.1007/ s00248-016-0918-2

Hansford KM, Fonville M, Jahfari S et al (2015) Borrelia miyamotoi in host-seeking Ixodes ricinus ticks in England. Epidemiol Infect 143:1079-1087. https://doi.org/10.1017/S0950268814001691

Hansford KM, Fonville M, Gillingham EL et al (2017) Ticks and Borrelia in urban and peri-urban green space habitats in a city in southern England. Ticks Tick Borne Dis 8:353-361. https://doi. org/10.1016/j.ttbdis.2016.12.009

Hovius JWR, De Wever B, Sohne M et al (2013) A case of meningoencephalitis by the relapsing fever spirochaete Borrelia miyamotoi in Europe. Lancet 382:658

Jahfari S, Hofhuis A, Fonville M et al (2016) Molecular detection of tick-borne pathogens in humans with tick bites and erythema migrans, in the Netherlands. PLoS Negl Trop Dis. https://doi.org/10.1371/ journal.pntd.0005042

Jongejan F, Uilenberg G (2004) The global importance of ticks. Parasitology 129(Suppl):S3-S14. https:// doi.org/10.1017/S0031182004005967 
Jungnick S, Margos G, Rieger M et al (2015) Borrelia burgdorferi sensu stricto and Borrelia afzelii: population structure and differential pathogenicity. Int J Med Microbiol 305:673-681. https://doi. org/10.1016/j.ijmm.2015.08.017

Karbowiak G, Biernat B, Stańczak J et al (2018) The role of particular ticks developmental stages in the circulation of tick-borne pathogens in Central Europe. 5. Borreliaceae 64:151-171. https://doi. org/10.17420/ap6403.147

Kiewra D, Stańczak J, Richter M (2014) Ixodes ricinus ticks (Acari, Ixodidae) as a vector of Borrelia burgdorferi sensu lato and Borrelia miyamotoi in Lower Silesia, Poland-preliminary study. Ticks Tick Borne Dis 5:892-897. https://doi.org/10.1016/j.ttbdis.2014.07.004

Kilpatrick AM, Dobson ADM, Levi T et al (2017) Lyme disease ecology in a changing world: consensus, uncertainty and critical gaps for improving control. Philos Trans R Soc B Biol, Sci, p 372

Kimura M (1980) A simple method for estimating evolutionary rates of base substitutions through comparative studies of nucleotide sequences. J Mol Evol 16:111-120. https://doi.org/10.1007/BF017 31581

Kowalec M, Szewczyk T, Welc-Falęciak R et al (2017) Ticks and the city-are there any differences between city parks and natural forests in terms of tick abundance and prevalence of spirochaetes? Parasites Vectors. https://doi.org/10.1186/s13071-017-2391-2

Krause PJ, Narasimhan S, Wormser GP et al (2013) Human Borrelia miyamotoi infection in the United States. N Engl J Med 368:291-293. https://doi.org/10.1056/NEJMc1215469

Kubiak K, Dziekońska-Rynko J (2006) Seasonal activity of the common European tick, Ixodes ricinus (Linnaeus, 1758), in the forested areas of the city of Olsztyn and its surroundings. Wiadomości Parazytol 52:59-64

Lane RS, Steinlein DB, Mun J (2004) Human behaviors elevating exposure to Ixodes pacificus (Acari: Ixodidae) nymphs and their associated bacterial zoonotic agents in a hardwood forest. J Med Entomol 41:239-248. https://doi.org/10.1603/0022-2585-41.2.239

Margos G, Vollmer SA, Ogden NH, Fish D (2011) Population genetics, taxonomy, phylogeny and evolution of Borrelia burgdorferi sensu lato. Infect Genet Evol 11:1545-1563

Margos G, Sing A, Fingerle V (2017) Published data do not support the notion that Borrelia valaisiana is human pathogenic. Infection 45:567-569. https://doi.org/10.1007/s15010-017-1032-1

May K, Jordan D, Fingerle V, Strube C (2015) Borrelia burgdorferi sensu lato and co-infections with Anaplasma phagocytophilum and Rickettsia spp. in Ixodes ricinus in Hamburg. Germany. Med Vet Entomol 29:425-429. https://doi.org/10.1111/mve.12125

Medlock JM, Hansford KM, Bormane A et al (2013) Driving forces for changes in geographical distribution of Ixodes ricinus ticks in Europe. Parasite Vectors 6:1-11. https://doi.org/10.1186/1756-3305-6-1

Medlock JM, Hansford KM, Vaux AGC et al (2018) Assessment of the public health threats posed by vector-borne disease in the United Kingdom (UK). Int J Environ Res Public Health. https://doi. org/10.3390/ijerph15102145

Molloy PJ, Telford SR, Chowdri HR et al (2015) Borrelia miyamotoi disease in the northeastern United States a case series. Ann Intern Med 163:91-98. https://doi.org/10.7326/M15-0333

NIH-PZH (2012) Infectious diseases and poisonings in Poland in 2015-2017. National Institute of Public Health-National Institute of Hygiene, Department of Epidemiology, Warsaw

Nowak-Chmura M (2013) Fauna kleszczy (Ixodida) Europy Środkowej. Wydawnictwo Naukowe Uniwersytetu Pedagogicznego, Kraków

Nunes M, Parreira R, Lopes N et al (2015) Molecular Identification of Borrelia miyamotoi in Ixodes ricinus from Portugal. Vector Borne Zoonotic Dis 15(8):515-7. https://doi.org/10.1089/vbz.2014.1765

Padgett KA, Bonilla DL (2011) Novel exposure sites for nymphal Ixodes pacificus within picnic areas. Ticks Tick Borne Dis 2:191-195. https://doi.org/10.1016/j.ttbdis.2011.07.002

Parola P, Paddock CD (2018) Travel and tick-borne diseases-lyme disease and beyond. Travel Med Infect Dis. https://doi.org/10.1016/j.tmaid.2018.09.010

Parola P, Raoult D (2001) Ticks and tick-borne bacterial diseases in humans: an emerging infectious threat. Clin Infect Dis 32:897-928. https://doi.org/10.1086/319347

Pawelczyk A, Sinski E (2001) Co-infection of Borrelia garinii and B. afzelii in a population of wild rodents from woodland. Wiad Parazytol 47:741-746

Pawelczyk A, Sinski E (2004) Prevalence of Ixodes ricinus infection with Borrelia burgdorferi s.l.: seasonal and annual variations. Wiad Parazytol 50:253-258

Platonov AE, Karan LS, Kolyasnikova NM et al (2011) Humans infected with relapsing fever spirochete Borrelia miyamotoi, Russia. Emerg Infect Dis 17:1816-1823. https://doi.org/10.3201/eid1710.101474

Pritt BS, Mead PS, Johnson DKH et al (2016) Identification of a novel pathogenic Borrelia species causing Lyme borreliosis with unusually high spirochaetaemia: a descriptive study. Lancet Infect Dis 16:556-564. https://doi.org/10.1016/S1473-3099(15)00464-8 
Randolph SE, EDEN-TBD sub-project team (2010) Human activities predominate in determining changing incidence of tick-borne encephalitis in Europe. Euro Surveill 15:24-31. https://doi.org/10.2807/ ese.15.27.19606-en

Reye AL, Hübschen JM, Sausy A, Muller CP (2010) Prevalence and seasonality of tick-borne pathogens in questing Ixodes ricinus ticks from Luxembourg. Appl Environ Microbiol 76:2923-2931. https:// doi.org/10.1128/AEM.03061-09

Richter D, Schlee DB, Matuschka FR (2003) Relapsing fever-like spirochetes infecting European vector tick of Lyme disease agent. Emerg Infect Dis 9:697-701. https://doi.org/10.3201/eid0906.020459

Rizzoli A, Silaghi C, Obiegala A et al (2014) Ixodes ricinus and its transmitted pathogens in urban and peri-urban areas in Europe: new hazards and relevance for public health. Front Public Heal 2:251. https://doi.org/10.3389/fpubh.2014.00251

Sato K, Takano A, Konnai S et al (2014) Human infections with Borrelia miyamotoi, Japan. Emerg Infect Dis 20:1391-1393. https://doi.org/10.3201/eid2008.131761

Schwarz A, Maier WA, Kistemann T, Kampen H (2009) Analysis of the distribution of the tick Ixodes ricinus L. (Acari: Ixodidae) in a nature reserve of western Germany using Geographic Information Systems. Int J Hyg Environ Health 212:87-96. https://doi.org/10.1016/j.ijheh.2007.12.001

Siuda K (1993) Kleszcze Polski (Acari: Ixodida). Systematyka i rozmieszczenie część II. (Ticks (Acari: Ixodida) of Poland. Part II taxonomy and distribution. Polskie Towarzystwo Parazytologiczne, Warszawa

Stańczak J, Kubica-Biernat B (1999) Prevalence of Borrelia burgdorferi in Ixodes ricinus ticks from different areas of Poland. Zentralblatt fur Bakteriologie 6:704-705

Stańczak J, Kubica-Biernat B, Racewicz M et al (2000) Detection of three genospecies of Borrelia burgdorferi sensu lato in Ixodes ricinus ticks collected in different regions of Poland. Int J Med Microbiol 290:559-566. https://doi.org/10.1016/S1438-4221(00)80022-3

Stanek G, Reiter M (2011) The expanding Lyme Borrelia complex-clinical significance of genomic species? Clin Microbiol Infect 17:487-493. https://doi.org/10.1111/J.1469-0691.2011.03492.X

Strnad M, Hönig V, Růžek D et al (2014) Europe-wide meta-analysis of Borrelia burgdorferi sensu lato prevalence in questing Ixodes ricinus ticks. Appl Environ Microbiol. https://doi.org/10.1128/aem.00609-17

Szekeres S, Coipan EC, Rigó K et al (2015) Eco-epidemiology of Borrelia miyamotoi and Lyme borreliosis spirochetes in a popular hunting and recreational forest area in Hungary. Parasit Vectors 8:309. https:// doi.org/10.1186/s13071-015-0922-2

Takano A, Toyomane K, Konnai S et al (2014) Tick surveillance for relapsing fever spirochete Borrelia miyamotoi in Hokkaido, Japan. PLoS ONE. https://doi.org/10.1371/journal.pone.0104532

Tamura K, Stecher G, Peterson D et al (2013) MEGA6: molecular evolutionary genetics analysis version 6.0. Mol Biol Evol 30:2725-2729

Tappe J, Jordan D, Janecek E et al (2014) Revisited: Borrelia burgdorferi sensu lato infections in hard ticks (Ixodes ricinus) in the city of Hanover (Germany). Parasit Vectors 7:441. https://doi. org/10.1186/1756-3305-7-441

Uspensky I (2014) Tick pests and vectors (Acari: Ixodoidea) in European towns: Introduction, persistence and management. Ticks Tick Borne Dis 5:41-47

Vorou RM, Papavassiliou VG, Tsiodras S (2007) Emerging zoonoses and vector-borne infections affecting humans in Europe. Epidemiol Infect 135:1231-1247. https://doi.org/10.1017/S0950268807008527

Vu Hai V, Almeras L, Socolovschi C et al (2014) Monitoring human tick-borne disease risk and tick bite exposure in Europe: available tools and promising future methods. Ticks Tick Borne Dis 5:607-619. https://doi.org/10.1016/j.ttbdis.2014.07.022

Wagemakers A, Staarink PJ, Sprong H, Hovius JWR (2015) Borrelia miyamotoi: a widespread tick-borne relapsing fever spirochete. Trends Parasitol 31:260-269. https://doi.org/10.1016/j.pt.2015.03.008

Wierzbicka A, Rączka G, Skorupski M et al (2016) Human behaviours elevating the risk of exposure to Ixodes ricinus larvae and nymphs in two types of lowland coniferous forests in west-central Poland. Ticks Tick Borne Dis 7:1180-1185. https://doi.org/10.1016/j.ttbdis.2016.07.018

Wodecka B (2011) flaB gene as a molecular marker for distinct identification of Borrelia species in environmental samples by the PCR-restriction fragment length polymorphism method. Appl Environ Microbiol 77:7088-7092. https://doi.org/10.1128/AEM.05437-11

Wodecka B, Leońska A, Skotarczak B (2010) A comparative analysis of molecular markers for the detection and identification of Borrelia spirochaetes in Ixodes ricinus. J Med Microbiol 59:309-314. https://doi. org/10.1099/jmm.0.013508-0

Publisher's Note Springer Nature remains neutral with regard to jurisdictional claims in published maps and institutional affiliations. 


\section{Affiliations}

\section{Katarzyna Kubiak ${ }^{1}$ (D) . Janina Dziekońska-Rynko² · Hanna Szymańska · Dariusz Kubiak $^{3}$ - Małgorzata Dmitryjuk ${ }^{4}$ Ewa Dzika ${ }^{1}$}

1 Department of Medical Biology, Faculty of Health Sciences, University of Warmia and Mazury in Olsztyn, Zolnierska 14c, 10-561 Olsztyn, Poland

2 Department of Zoology, Faculty of Biology and Biotechnology, University of Warmia and Mazury in Olsztyn, Oczapowskiego 2, 10-719 Olsztyn, Poland

3 Department of Microbiology and Mycology, Faculty of Biology and Biotechnology, University of Warmia and Mazury in Olsztyn, Oczapowskiego 2, 10-719 Olsztyn, Poland

4 Department of Biochemistry, Faculty of Biology and Biotechnology, University Warmia and Mazury in Olsztyn, Oczapowskiego 1A, 10-719 Olsztyn, Poland 